\title{
UJI SITOTOKSIK DENGAN METODE BRINE SHRIMP LETHALITY TEST DAN PROFIL METABOLIT SEKUNDER DARI EKSTRAK BIJI BUAH BERENUK (Crescentia cujete Linn)
}

\author{
Afdhil Arel ${ }^{* 1)}$ \\ ${ }^{1,}$ Universitas Muhammadiyah sumatera Barat \\ Jalan Pasie Nan Tigo Koto Tangah Padang \\ Email: afdhil.arel@yahoo.com
}

\section{INTISARI}

Penelitian untuk mengetahui profil metabolit sekunder yang terdapat dalam ekstrak biji (Crescentia cujete Linn.) Dan uji sitotoksik terhadap larva udang Artemia salina Leach dengan metode BSLT. Uji fitokimia menunjukkan bahwa ekstrak diharapkan mengandung senyawa terpenoid, alkaloid, fenolik, senyawa metabolit sekunder. Hasil analisis kualitatif dengan TLC positif mengandung fenolat. Hasil identifikasi dengan Spectrophotometer UV-vis untuk penentuan panjang gelombang maksimal dari ekstrak biji berenuk yang terdiri dari 3 puncak dengan panjang gelombang maksimal $326 \mathrm{~nm}, 258 \mathrm{~nm}, 222 \mathrm{~nm}$ diharapkan senyawa terpenoid, alkaloid, dan fenolik. Hasil uji toksisitas menggunakan larva udang (Artemia salina leach) dibagi menjadi 4 kelompok: 1 kelompok kontrol dan 3 kelompok seri konsentrasi. Konsentrasi larutan uji yang digunakan adalah 1.000, 100 dan $10 \mu \mathrm{g} / \mathrm{ml}$. Kematian larva udang diamati setelah 24 jam perawatan. Berdasarkan analisis dengan metode probit, nilai LC50 ekstrak biji berenuk terhadap larva udang Artemia salina Leach adalah sebesar $82,30 \mu \mathrm{g} / \mathrm{ml}$. Hal ini menunjukkan bahwa ekstrak berenuk beri merupakan racun bagi larva udang Artemia salina Leach, adanya kandungan terpenoid, alkaloid dan fenolat dalam ekstrak biji berenuk.

Kata Kunci : Berenuk; Metabolit Sekunder; Sitotoksik.

\begin{abstract}
The purpose of this research is to find out the profile of secondary metabolite contained in the extract of seeds (Crescentia cujete Linn.) And cytotoxic test against shrimp larvae Artemia salina Leach by BSLT method. Phytochemical tests showed that the extract be expected contained the terpenoid, alkaloid, phenolic, secondary metabolite compounds. The results of qualitative analysis with positive TLC contains phenolics. The result of identification with Spectrophotometer UV-vis for determination of $\alpha$ max from berenuk seeds extract consisted of 3 peaks with $\alpha$ max $326 \mathrm{~nm}, 258 \mathrm{~nm}, 222 \mathrm{~nm}$ be expected terpenoid compound, alkaloid, and phenolic. The results of toxicity test using shrimp larvae (Artemia salina leach) were divided into 4 groups: 1 control group and 3 groups of concentration series. The concentration of test solution used was 1,000, 100 and $10 \mu \mathrm{g} / \mathrm{ml}$. The shrimp larvae mortality was observed after 24 hours of treatment. Based on the analysis with probit method, $\mathrm{LC}_{50}$ value of seed extract berenuk to shrimp larvae Artemia salina Leach is equal to $82,30 \mu \mathrm{g} / \mathrm{ml}$. This shows that the extract of berenuk berries is toxic to shrimp larvae Artemia salina Leach, presence to terpenoid content, alkaloids and phenolics in the extract of seeds berenuk.
\end{abstract}

Keywords : Secondary metabolite; Cytotoxic; BSLT.

Corresponding author:

Afdhil Arel

Universitas Muhammadiyah Sumatera Barat

Jalan Pasie Nan Tigo Koto Tangah Padang

Email:afdhil.arel@yahoo.com 


\section{PENDAHULUAN}

Pada umumnya senyawa metabolit sekunder yang terdapat di dalam tumbuhan adalah alkaloid, flavonoid, triterpenoid, steroid, saponin. Senyawa tersebut memiliki aktivitas biologis yang berperan sebagai pelindung pada tumbuhan dari gangguan hama penyakit maupun lingkungan, dan dapat digunakan dalam dunia pengobatan (Dapas et al 2014; Hariana, 2008).

Salah satu tanaman yang berpotensi dikembangkan dalam dunia pengobatan adalah tanaman berenuk (Crescentia cujete), tanaman ini tidak pernah dikonsumsi oleh masyarakat, namun mengandung khasiat yang sangat besar di bidang kesehatan. Umumnya tanaman berenuk (Crescentia cujete) hanya digunakan untuk pembuatan alat- alat rumah tangga yang dibuat dari kulit buah dan batangnya (Imaroh, 2013). Tanaman berenuk banyak mengandung senyawa metabolit sekunder, seperti pada daun dan batangnya terdapat senyawa polifenol dan saponin, sedangkan daging buah berenuk terdapat senyawa alkaloid, flavonoid, dan tannin (Rinawati, 2011).

Berenuk merupakan tanaman perdu tropis yang berkhasiat sebagai obat berbagai penyakit. Daun berenuk dalam pengobatan tradisional digunakan untuk mengobati luka baru dan menurunkan hipertensi. Daun mudanya ditumbuk dan dijadikan pengkompres untuk sakit kepala dan luka. Sementara daging buahnya digunakan untuk mengobati diare, flu, bronkhitis, batuk, asma, dan uretritis (Heyne, 1987). Penelitian ilmiah mengenai berenuk masih sangat jarang, namun tanaman ini memiliki potensi yang cukup menjanjikan sebagai obat herbal.

Selain itu uji fitokimia yang dilakukan dalam penelitian Rinawati (2011), memberikan informasi bahwa daging buah berenuk mengandung alkaloid, flavonoid, saponin, tanin, dan polifenol. Kandungan alkaloid, saponin, tanin, dan polifenolnya berpotensi sebagai zat antibakteri.

Berdasarkan khasiat dan hasil penelitian di atas maka tanaman berenuk (Crescentia cujete L.) potensial untuk dikembangkan menjadi suatu obat, terutama bagian biji buah berenuk, karena belum dilakukannya penelitian terhadap biji buah tanaman ini. Penelitian ini menfokuskan pada penentuan profil metabolit sekunder dan menguji sitotoksik ekstrak biji buah berenuk terhadap larva udang laut (Artemia salina Leach) dengan mengunakan metode Brine Shrimp Lethality Test (BSLT).

\section{METODE PENELITIAN \\ Bahan Penelitian}

Bahan-bahan yang digunakan adalah Ekstrak kental biji buah berenuk (Crescentia cujete), Plat silika 60 GF 254, etil asetat, n-heksan, air laut, etanol 70\% dan etanol $96 \%$, kloroform, amoniak, asam sulfat, asam asetat glasial, larva Artemia salina Leach, Dimetilsulfoksida (DMSO).

\section{Alat Penelitian}

Metode penelitian meliputi alat yang digunakan adalah : rotary evaporator, desikator, vial yang telah dikalibrasi, gelas kimia, pipet mikro, media pembiakan Artemia salina Leach, aerator, lampu penerang, kertas saring, spetrofotometer UV-visible, lampu UV dengan panjang gelombang $254 \mathrm{~nm}$ dan $365 \mathrm{~nm}$, seperangkat alat kromatografi lapis tipis.

\section{JALANNNYA PENELITIAN}

\section{Ekstraksi Sampel Biji Buah Berenuk (Crescentia cujete) (Departemen Kesehatan RI, 2000)}

Ekstraksi sampel sebanyak 250 g dilakukan dengan metoda maserasi (perendaman). Biji buah berenuk (Crescentia cujete) yang telah dikeringkan digerus dalam lumpang dimasukkan ke dalam botol berwarna gelap, direndam dengan etanol 70\% selama 3 hari dan disimpan ditempat gelap sambil sesekali diaduk. Setelah 3 hari perendaman, disaring dan ampasnya direndam kembali dengan etanol 96 $\%$ dalam jangka waktu yang sama. Maserasi yang ketiga kali juga direndam menggunakan etanol 96\%, dengan tujuan mengikat air dalam larutan. Penyarian ini dilakukan sampai diperoleh maserat yang jernih dengan cara yang sama dan seluruh filtrat digabung menjadi satu dan diaduk hingga rata, kemudian diuapkan dengan rotary evaporator sampai didapatkan ekstrak kental.

\section{Pengujian Sitotoksisitas Ekstrak Biji Buah Berenuk (Crescentia cujete) Dengan Metode Brine Shrimp Lethality Test.}


Disiapkan 9 vial untuk tiga konsentrasi masing- masing larutan uji $10 \mu \mathrm{g} / \mathrm{ml}, 100 \mu \mathrm{g} / \mathrm{ml}$, dan $1000 \mu \mathrm{g} / \mathrm{ml}$ serta 1 vial untuk kontrol. Larutan induk dibuat dengan melarutkan $40 \mathrm{mg}$ ekstrak kental dalam $4 \mathrm{~mL}$ etanol $96 \%$. Larutan induk tersebut sebanyak $5 \mu \mathrm{g} / \mathrm{ml}, 50 \mu \mathrm{g} / \mathrm{ml}$, dan $500 \mu \mathrm{g} / \mathrm{ml}$ berturutturut dimasukkan kedalam masing-masing vial yang telah disiapkan untuk konsentrasi 1000, 100,10 $\mu \mathrm{g} / \mathrm{ml}$. Vial yang berisi larutan uji dikeringkan dalam desikator sampai semua pelarutnya menguap, kemudian ditambahkan $50 \mu \mathrm{L}$ DMSO termasuk vial kontrol untuk melarutkan sampel kembali. Selanjutnya ditambah 3,5 mL air laut.

Larva Artemia salina Leach sebanyak 10 ekor dimasukkan kedalam setiap larutan uji dan kontrol, dicukupkan volumenya sampai $5 \mathrm{ml}$ dengan air laut, diletakkan dibawah sinar lampu selama 24 jam. Setelah 24 jam diamati dan dihitung jumlah larva udang yang mati.

\section{ANALISIS DATA.}

Dari data yang diperoleh, dihitung nilai $\mathrm{LC}_{50}$ dengan analisis probit (Adfa, 2005) Apabila nilai $\mathrm{LC}_{50}<$ 30 ppm maka ekstrak dikatakan sangat toksik, $\mathrm{LC}_{50} \leq 1000 \mathrm{ppm}$ toksik, dan $\mathrm{LC}_{50}>1000$ ppm tidak toksik (Sumihe, Liwas, 2013)

\section{Hasil dan Pembahasan}

Sampel kering biji berenuk (Crescentia cujete Linn) dengan berat 250 gram, setelah dimaserasi dan diuapkan dengan rotary evaporator diperoleh ekstrak kental etanol sebanyak 21,831 gram dengan rendemen 8,732 \%. Kemudiaan ekstrak kental biji berenuk dianalisis kandungan senyawa metabolit sekunder dengan uji fitokimia yang dilakukan sebagai uji pendahuluan untuk mengetahui tentang kandungan senyawa bioaktif yang terkandung di dalam biji berenuk. Hasil uji fitokimia ekstrak etanol bijiberenuk menunjukkan adanya kandungan senyawa bioaktif seperti fenolat, terpenoid dan alkaloid.

Tabel I. Hasil Uji Fitokimia biji buah berenuk

\begin{tabular}{ccc}
\hline Uji Fitokimia & Pereaksi & Hasil \\
\hline Alkaloid & Mayer & + \\
& Wagner & + \\
Fenolik & Dragendorff & + \\
Flavonoid & $\mathrm{FeCl}_{3}$ & + \\
Saponin & Sianidin test & - \\
Uji steroid & Forth test & - \\
Terpenoid & $\mathrm{CH}_{3} \mathrm{COOH}+\mathrm{H}_{2} \mathrm{SO}_{4}$ & - \\
& $\mathrm{CH}_{3} \mathrm{COOH}+\mathrm{H}_{2} \mathrm{SO}_{4}$ & + \\
\hline
\end{tabular}

Analisis ekstrak biji berenuk mengunakan kromatografi lapis tipis dengan eluen nheksan : etil asetat (7:3). Hasil elusi KLT dimonitor dengan beberapa penampak noda antara lain UV 254 nm, UV 365 nm, H2SO4 $10 \%, \mathrm{FeCl} 3$, dan dragendrof.

Penampak noda ini digunakan untuk memunculkan noda-noda yang tidak tampak dengan sinar UV dan juga untuk menunjukkan golongan dari senyawa yang terkandung dalam ekstrak biji berenuk.

Tabel II. Profil Kromatografi Lapis Tipis Ekstrak Biji Berenuk

\begin{tabular}{|c|c|c|c|c|c|c|}
\hline \multirow[t]{2}{*}{ No } & \multirow[t]{2}{*}{$\mathbf{R f}$} & \multicolumn{5}{|c|}{ Penampak Noda } \\
\hline & & UV 254 nm & UV 365 nm & $\mathrm{FeCl}_{3}$ & $\mathrm{H}_{2} \mathrm{SO}_{4}$ & Dragendrof \\
\hline 1 & 0.7 & Ungu pekat & - & - & $\begin{array}{l}\text { Fluorosensi Biru } \\
\text { terang }\end{array}$ & $\begin{array}{c}\text { Kuning } \\
\text { Pekat }\end{array}$ \\
\hline 2 & 0.5 & Ungu pekat & - & - & $\begin{array}{l}\text { Fluorosensi Biru } \\
\text { terang }\end{array}$ & $\begin{array}{c}\text { Kuning } \\
\text { Pekat }\end{array}$ \\
\hline 3 & 0.3 & - & - & - & $\begin{array}{l}\text { Fluorosensi Biru } \\
\text { terang }\end{array}$ & - \\
\hline 4 & 0.2 & Coklat muda & Coklat muda & $\begin{array}{c}\text { Coklat } \\
\text { kehitaman }\end{array}$ & $\begin{array}{l}\text { Fluorosensi Biru } \\
\text { terang }\end{array}$ & - \\
\hline
\end{tabular}


Berdasarkan profil kromatografi lapis tipis ekstak biji berenuk dengan eluen dan penampak noda tersebut diatas golongan senyawa utama dari biji berenuk adalah golongan fenolat. Apabila dilakukan prosedur elusi kromatografi lapis tipis mengunakan eluen yang berbeda bisa jadi akan diperoleh profil yang lebih baik lagi dari ekstrak biji berenuk ini.

Identifikasi dengan mengunakan Spektrofotometer UV-Vis, dengan menentukan panjang gelombang maksimum dari senyawa yang diduga terpenoid, alkaloid dan fenolat yang tedapat dalam ekstrak, dimana ekstrak kental dibuat dengan konsentrasi $700 \mu \mathrm{g} / \mathrm{ml}$, dari hasil yang di peroleh ternyata terdapat 3 puncak yaitu pada panjang gelombang $326 \mathrm{~nm}, 258 \mathrm{~nm}$, dan $222 \mathrm{~nm}$, dengan absorbansi 0.230, 0.837, dan 0.718 .

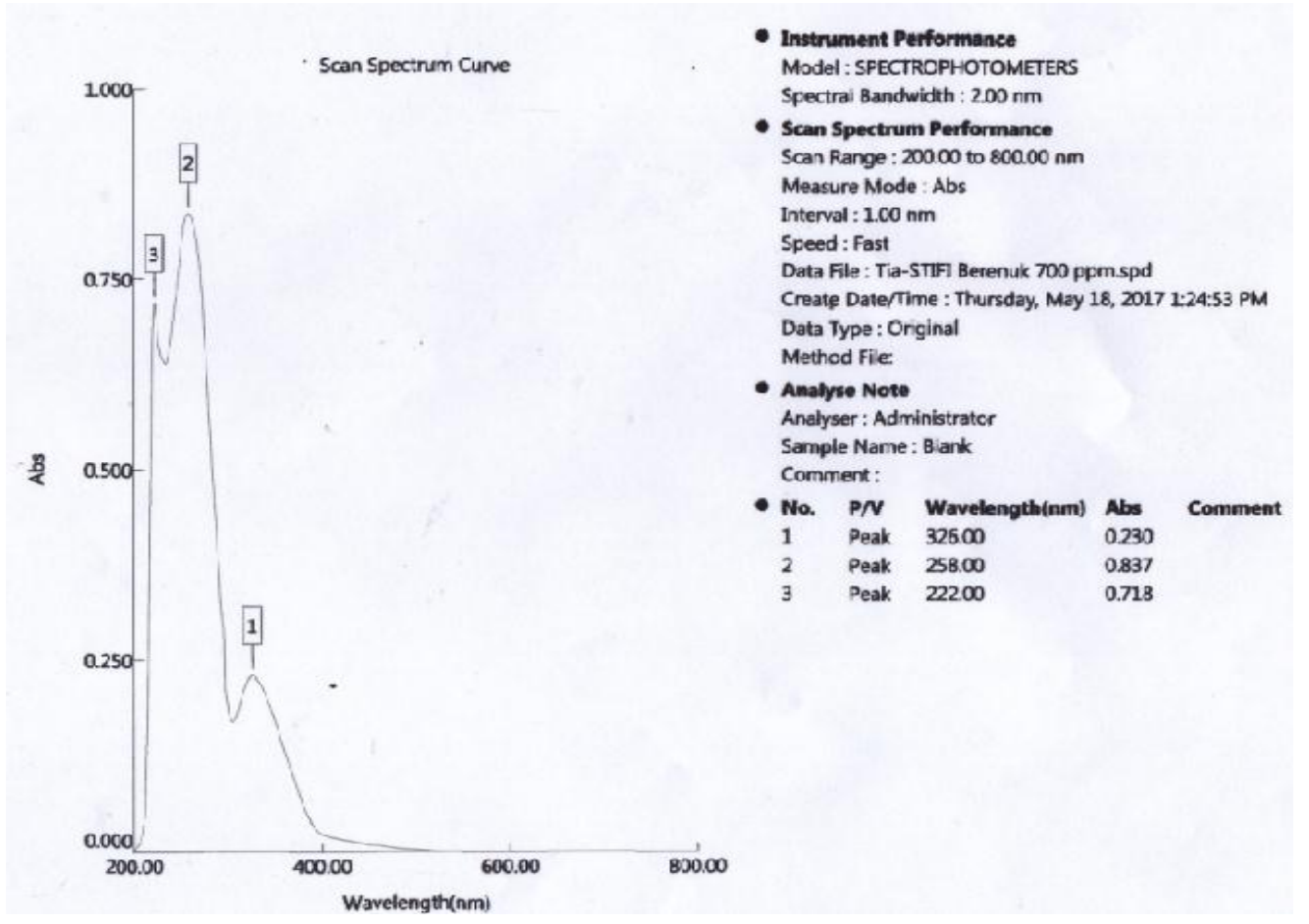

Gambar 1. Uji Panjang Gelombang Ekstrak Biji Berenuk dengan Spektrofotometer UV-Vis

Pengujian aktivitas sitotoksik digunakan metode Brine Shrimp Lethality Test mengunakan larva udang Artemia salina Leach. Larva Artemia salina Leach memiliki kemampuan berkembang biak yang cepat seperti sel kanker. Kesamaan lain yang dimiliki Artemia salina Leach adalah membran kulitnya yang tipis seperti sel kanker. Kandungan senyawa metabolit sekunder yang ada dalam ekstrak biji berenuk diharapkan mampu menghambat metabolisme pada larva Artemia salina Leach dan menyebabkan kematian (Wardana, 2013)

Dimetil sulfoksida (DMSO) digunakan melarutkan ekstrak. Penambahan DMSO ke dalam vial uji bertujuan untuk membantu melarutkan senyawa yang sukar larut dalam air laut sehingga terdistribusi merata. DMSO yang ditambahkan sebanyak $50 \mu \mathrm{L}$ karena di atas nilai tersebut DMSO dapat menyebabkan kematian pada larva (Priyanto, 2009).

Nilai LC $_{50}$ yang diperoleh dari hasil uji aktivitas sitotoksik yang dilakukan pada ekstrak biji berenuk menunjukkan bahwan biji berenuk memiliki aktivitas sitotoksik, karena nilai $\mathrm{LC}_{50}$ kecil dari $1000 \mu \mathrm{g} / \mathrm{ml}$. Sitotoksik adalah kemampuan suatu senyawa menghambat pertumbuhan sel, dimana suatu ekstrak dinyatakan aktif sitotoksik apabila nilai $\mathrm{LC}_{50}$ kecil dari $1000 \mu \mathrm{g} / \mathrm{ml}$. Nilai $\mathrm{LC}_{50}$ dari ekstrak biji berenuk 82,30 $\mu \mathrm{g} / \mathrm{ml} \mathrm{kecil}$ dari $1000 \mu \mathrm{g} / \mathrm{ml}$ maka ekstrak biji berenuk ini dapat di kategorikan toksik (Mayer, 1982). 
Tabel III. Hasil pemeriksaan aktivitas sitotoksik dari ekstrak biji berenuk

\begin{tabular}{ccccccc}
\hline $\begin{array}{c}\text { Konsentrasi } \\
(\mathbf{p p m})\end{array}$ & $\begin{array}{c}\text { Log } \\
\text { Konsentrasi }\end{array}$ & Pengulangan Hewan/Kmpk. & $\begin{array}{c}\text { Hewan yg } \\
\text { Mati }\end{array}$ & $\begin{array}{c}\text { \% } \\
\text { Kematian }\end{array}$ & Nilai Probit \\
\hline 1000 & 3 & 1 & 10 & 9 & & \\
& & 2 & 10 & 8 & $83,33 \%$ & 5,967 \\
& & 3 & 10 & 8 & & \\
100 & 2 & 1 & 10 & 3 & & \\
& & 2 & 10 & 4 & $40 \%$ & 4,747 \\
& & 3 & 10 & 5 & & \\
10 & 1 & 1 & 10 & 3 & & \\
& & 2 & 10 & 3 & $30 \%$ & 4,476 \\
& & 3 & 10 & 3 & & \\
\hline
\end{tabular}

\section{KESIMPULAN}

Berdasarkan uji fitokimia, KLT, dan Spektrofotometer UV-vis, ekstrak biji buah berenuk (Crescentia cujete Linn) diduga mengandung senyawa metabolit sekunder golongan alkaloid, fenolik, dan terpenoid. Biji buah berenuk (Crescentia cujete Linn) memiliki potensi toksik terhadap larva Artemia salina Leach melalui uji BSLT dengan LC $_{50}$ sebesar 82,30 $\mu \mathrm{g} / \mathrm{ml}$.

\section{UCAPAN TERIMA KASIH}

Terima kasih kepada rekan-rekan yang telah membantu dalam proses penelitian ini. Sehingga penelitian ini dapat diselesaikan. Semoga bermanfaat untuk semua.

\section{DAFTAR PUSTAKA}

Dapas, C. C., Koleangan, H. S. J., Sangi, M, 2014, Analisis Senyawa Metabolit Sekunder dan Uji Toksisitas Ekstrak Batang Bawang Laut (Proiphys amboinensis ( L .), fakultas MIPA Unsrat Manado, Jurnal, 144-148.

Departemen Kesehatan RI, 2000, Parameter Standar Umum Ekstrak Tumbuhan Obat, Edisi pertama, Direktorat Jenderal Pengawasan Obat dan Makanan, Jakarta.

Hariana, 2008, Tumbuhan Obat Dan Khasiatnya Seri 2, Penebar Swadaya, Jakarta.

Heyne, k., 1987, Tumbuhan Berguna Indonesia Jilid II.Badan Litbang Kehutanan, Jakarta.

Imaroh, R., 2013, Potensi Ekstrak Daun Berenuk (Crescentia cujete) Sebagai Terapi

Alternatif Penyakit Jantung Koroner Dengan Menurunkan Risiko Pembentukan Aterossklerosis. Universitas Muhammadiyah, Jakarta.

Mayer, B. N., N. R. Ferrigni, J. E. Putnam, L. B. Jacobsen, D. E. Nichols, and J. L. M., 1982,

Brine Shrimps $\square$ : A Convenient General Bioassay for Active Plant Constituent”, J. of Medical Plant Research Planta Medica, 45, 31-34.

Priyanto, 2009, Toksikologi: Mekanisme Terapi Antidotum dan Penilaian Resiko, Sunaryo Ed, Lembaga Studi dan Konsultasi Farmakologi, Jakarta.

Rinawati, 2011, Daya Antibakteri Tumbuhan Majapahit ( Crescentia cujete L .) Terhadap Bakteri Vibrio alginolyticus. Jurnal, 1-13.

Sumihe, G., Liwas, D., 2013, Phytochemical analysis and Determining LC $_{50}$ Value of Liwas Leave Methanol Extract, 1- 4.

Wardana, luthfi, 2013, Uji bioaktivitas fraksi n-heksan ekstrak etanol kulit batang karet india, Naskah Publikasi, hal 1-17. 